

\section{Nuestro efluente no cumple los requisitos legales para la descarga: ¿por dónde empezar?}

1 agua experimenta una variación negativa de su calidad cada vez que es utilizada, pues la disminución de la calidad se encuentra asociada a la presencia de Justancias no deseables. De manera ideal, la presencia de estas sustancias debería controlarse en el origen, pero si esto no es posible, se requerirá de un sistema que remueva dichas sustancias antes de la descarga. Este artículo presenta, de manera resumida, las etapas necesarias para encontrar una solución al problema de cómo tratar un efluente.

\section{Por Javier Quino}


El agua utilizada en cualquier actividad doméstica 0 industrial experimenta un cambio negativo en su calidad. Este cambio ha sido ejemplificado en la denominada cascada del agua, en la que el uso potencial de esta se correlaciona directamente con su calidad. Mientras el uso del agua empeora su calidad, su tratamiento la mejora. El concepto de cascada expresa la necesidad de tratar el agua previamente utilizada para adecuarla a una necesidad específica y lograr su uso sostenible (Holt, Barton y Mitchell, 2005).

Con alta frecuencia, el agua proveniente de procesos industriales necesita ser vertida a un cuerpo receptor. La ley determina las características que debe poseer el agua antes de ser descargada, y estas están acordes a la actividad de donde proviene. Por ejemplo, en el Perú, el Decreto Supremo 010-2010-MINAM establece los límites máximos permisibles (LMP) para la descarga de efluentes líquidos de actividades minerometalúrgicas. Estos efluentes líquidos poseen características que van a diferir sensiblemente de las descargas procedentes de actividades productivas diferentes, o inclusive de actividades idénticas y aún en la

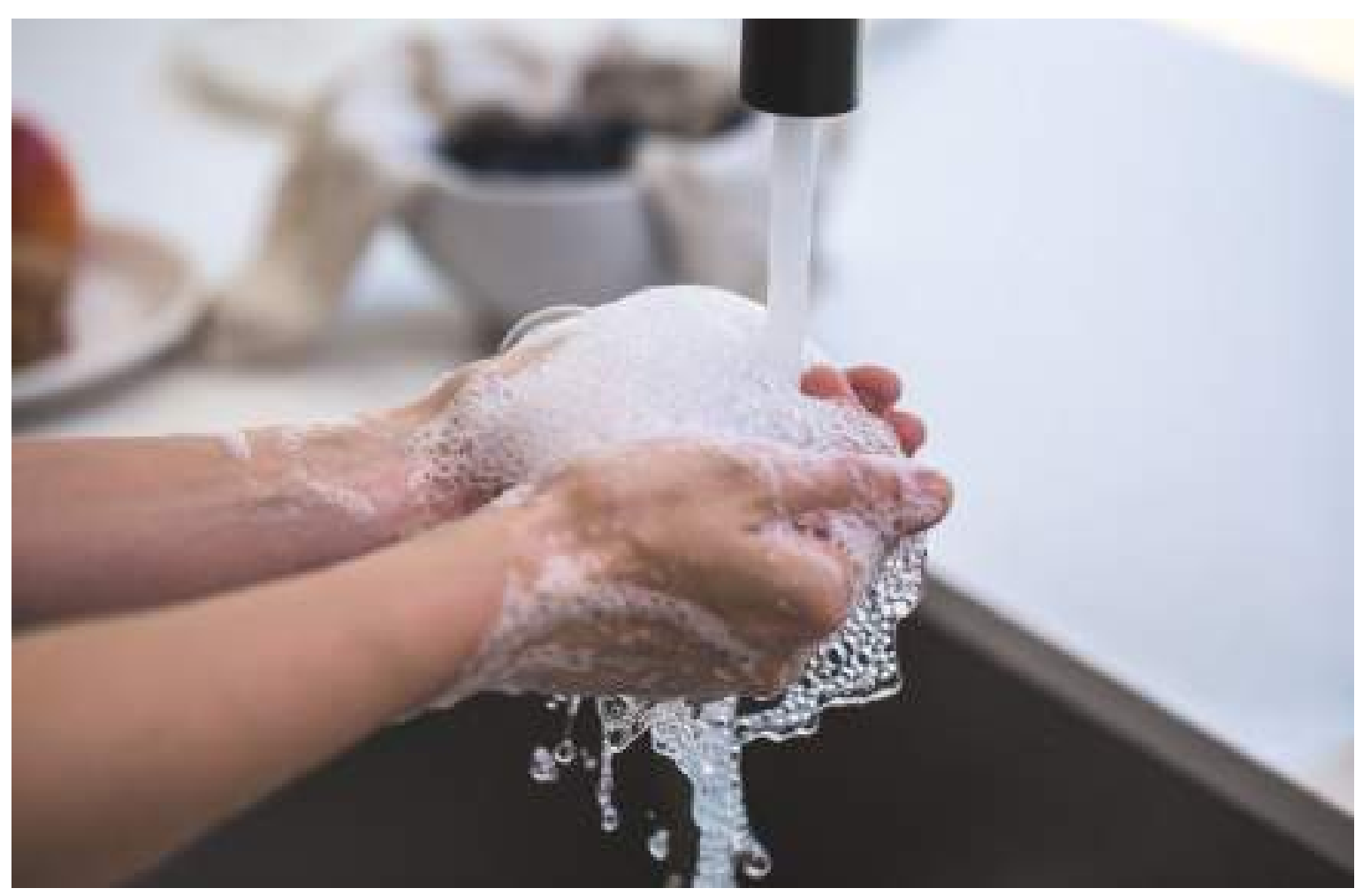

Figura 1. Agua potable

Fuente: Burst, s. f. misma operación. Cada efluente es diferente a los demás.

El proceso de decidir el tipo de tratamiento que requerirá un efluente antes de ser descargado a un cuerpo receptor empieza por la comparación de las características del efluente y de la norma asociada al efluente de dicha actividad. Si las características de este no cumplen la norma, será necesario preguntarse si es posible realizar el control en la fuente.

El control en la fuente - una estrategia para la prevención de la contaminación - debe ser siempre el primer acercamiento al problema, pues es mejor que una respuesta de control de la contaminación (conocida también como el enfoque al final del tubo). El caso coreano es ilustrativo: la economía creció cientos de veces en las últimas décadas, pero fue articulada con mejoras en el desempeño ambiental. El corolario de las acciones de prevención fue "la mejora en el desempeño ambiental se traduce en una mejora del desempeño financiero" (Lee y Rhee, 2005).

La secuencia de decisiones para el desarrollo y la implementación de una estrategia efectiva para el tratamiento de aguas residuales ha sido

extenderse a todas las fuentes que lo producen. Una comprensión completa acerca de cómo el agua se produce es tan importante como saber cuáles son las sustancias contaminantes presentes (McLaughlin et al., 1992).

Los contaminantes que se desea caracterizar dependerán del origen del agua y pueden ser compuestos orgánicos solubles, sólidos suspendidos, metales pesados, metaloides, compuestos orgánicos tóxicos, nitrógeno y fósforo, sustancias refractarias a la biodegradación, aceites y compuestos volátiles, así como cambios en el color y la turbidez (Eckenfelder, 2000). Los compuestos 


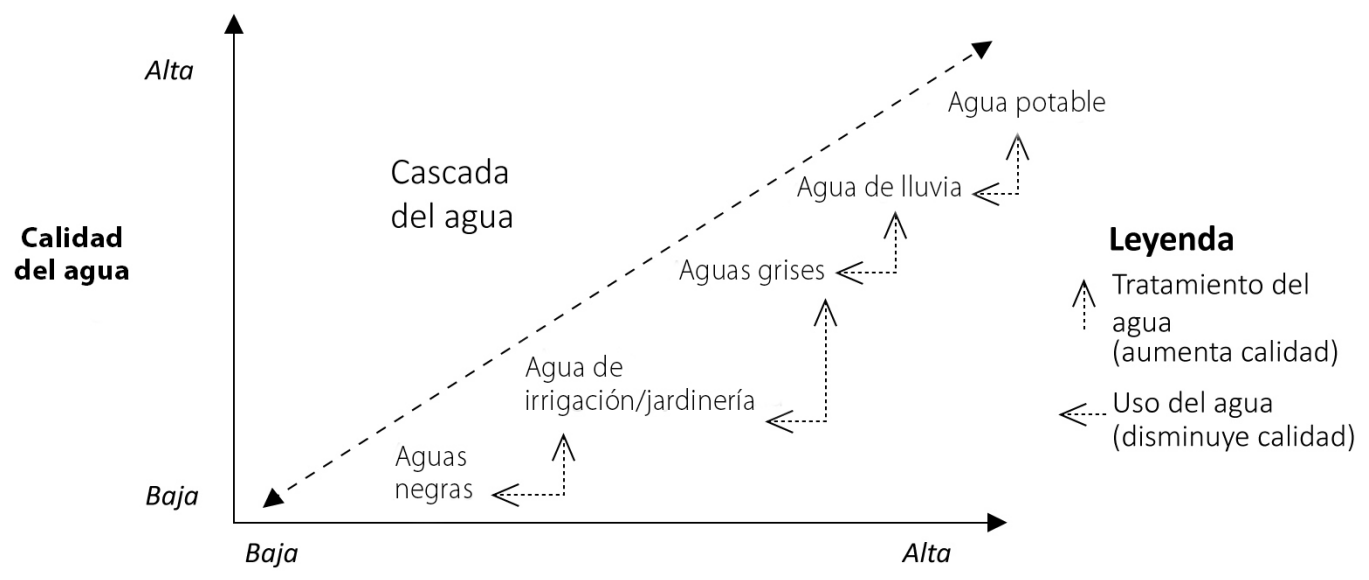

Utilidad potencial

Figura 3. Relación de la cascada del agua entre calidad y utilidad potencial Fuente: Holt, Barton y Mitchell, 2005

orgánicos solubles producen el consumo del oxígeno en las aguas del cuerpo receptor. Los sólidos suspendidos perturban la vida acuática al acumularse en las zonas de menor caudal, y ya que también contienen materia orgánica, su descomposición consume el oxígeno disuelto en el agua. Los metales pesados (como el mercurio y el cadmio) y algunos metaloides (como el arsénico) son tóxicos para la vida acuática. El nitrógeno y el fósforo son nutrientes que al ser descargados provocan la eutrofización de los cuerpos receptores del agua residual, lo que conduce a un crecimiento no deseado de las algas. El color y la turbidez son, fundamentalmente, un problema estético.

Como puede verse, los componentes químicos de las aguas residuales se encuentran distribuidos en dos grupos: los componentes inorgánicos (fósforo y nitrógeno, ácidos, sales, metales, metaloides y gases) y los componentes orgánicos. Los contaminantes orgánicos, por lo general, se describen colectivamente como la demanda química de oxígeno (DQO), la demanda biológica de oxígeno (DBO) y el carbono orgánico total (TOC, por sus siglas en inglés).

\section{Wastewater survey}

Una vez que se estableció la necesidad de tratar el agua — en virtud de la normativa vigente y en ausencia de la posibilidad del control en fuente-, se debe realizar un inventario de las fuentes de esta, los caudales y sus variaciones, la distribución y las frecuencias de descarga de dichos componentes. Cada flujo debe ser analizado para determinar la frecuencia con la que se produce, la duración, el caudal y la composición,

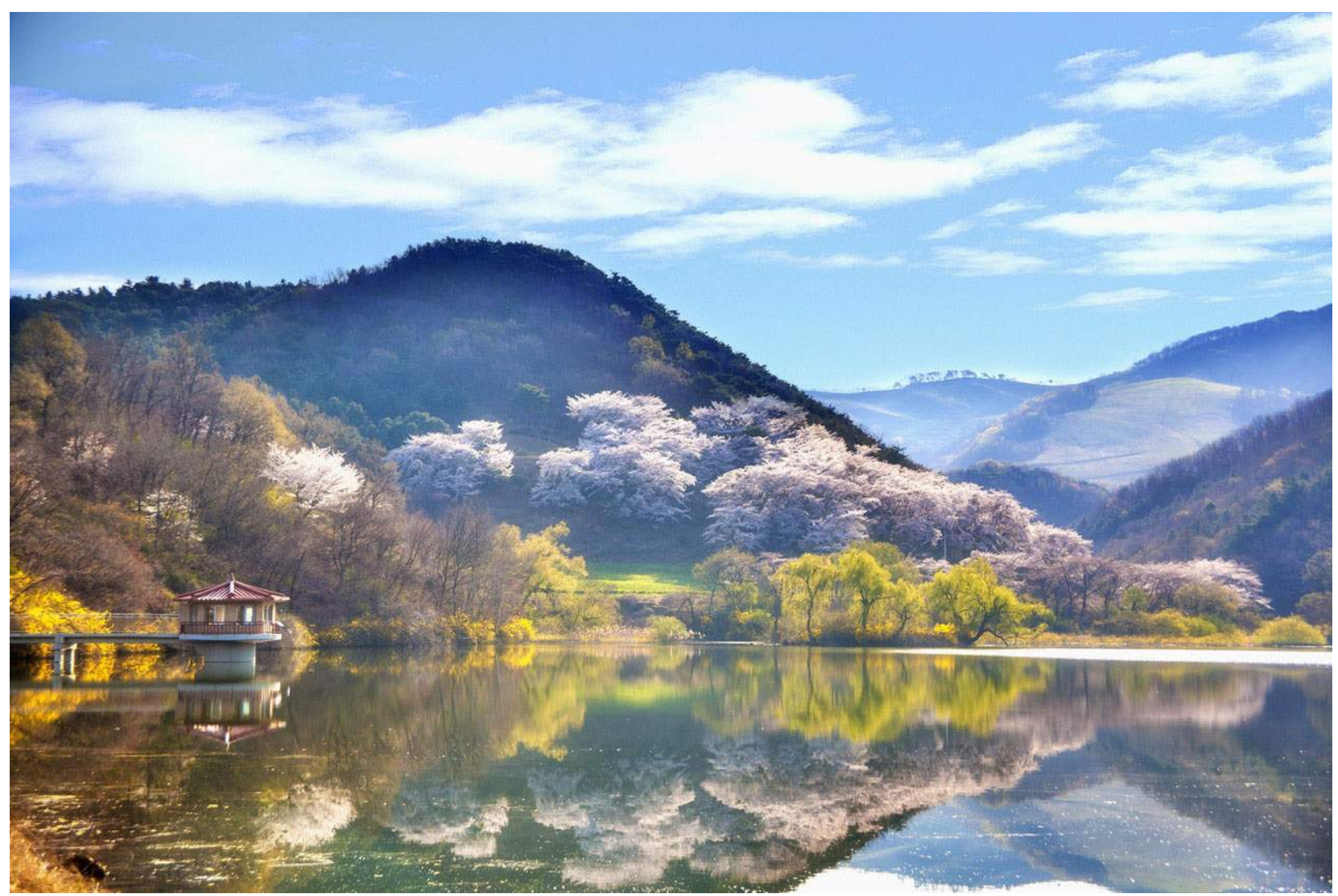

Figura 4. Aguas de Corea

Fuente: Pixabay, s. f. 
pues estos elementos determinarán las características del efluente final $y$, por ende, la representatividad del muestreo.

Para que un muestreo sea exitoso, se requiere alcanzar los siguientes criterios mínimos (Water Environment Federation, 2008):

- Los datos obtenidos deben responder las preguntas que motivaron el esfuerzo de muestrear y analizar el efluente.

- Los datos obtenidos deben ser representativos de los componentes, los flujos y la variabilidad del efluente.

- Los métodos analíticos deben ser apropiados para el objetivo que se persigue.

- El programa de análisis y muestreo debe ser económico.

Estos criterios permitirán saber si el efluente cumple o no con los límites, el origen de los contaminantes y si es posible aplicar el control en la fuente. Los protocolos de muestreo difieren si los efluentes son continuos o no, si provienen directamente de las operaciones o pasan por un sistema previo antes de la descarga.

Si los datos van a ser utilizados para proporcionar información general acerca de las características del agua, bastará un número pequeño de muestras; este tipo de muestreo es económico, pero no es preciso para una caracterización completa. Si los datos serán utilizados para el diseño de las facilidades del tratamiento, entonces se debe realizar un muestreo sistemático; esto asegura que los datos sean representativos -en volumen y composicióndel efluente en cuestión. Algunas veces el muestreo es muy específico, dependiendo del parámetro que se desea medir (Rice, Baird y Eaton, 2017). La toma de muestras debe ser ejecutada por personal entrenado: si las muestras no son representativas, los resultados no van a contribuir con la solución que se busca. Los responsables de la operación deben estar al tanto del programa de muestreo para evitar variaciones planeadas (limpieza de tanques y reemplazo de insumos) que modifiquen las características del efluente más allá de las variaciones esperadas durante la operación normal.

Los métodos de análisis deben ser seleccionados con base en su confiabilidad, sus límites de detección y la susceptibilidad que tienen frente a las interferencias. El programa de análisis se elabora para ser coherente con los objetivos que persigue el estudio: la complejidad y la precisión de los métodos analíticos y del muestreo deben ser tantas como sea requerida por el programa, ni más ni menos (Water Environment Federation, 2008). Esto es relevante porque una práctica frecuente es solicitar una gran cantidad de análisis de cuyos resultados solo una pequeña parte contribuye con la solución del problema.

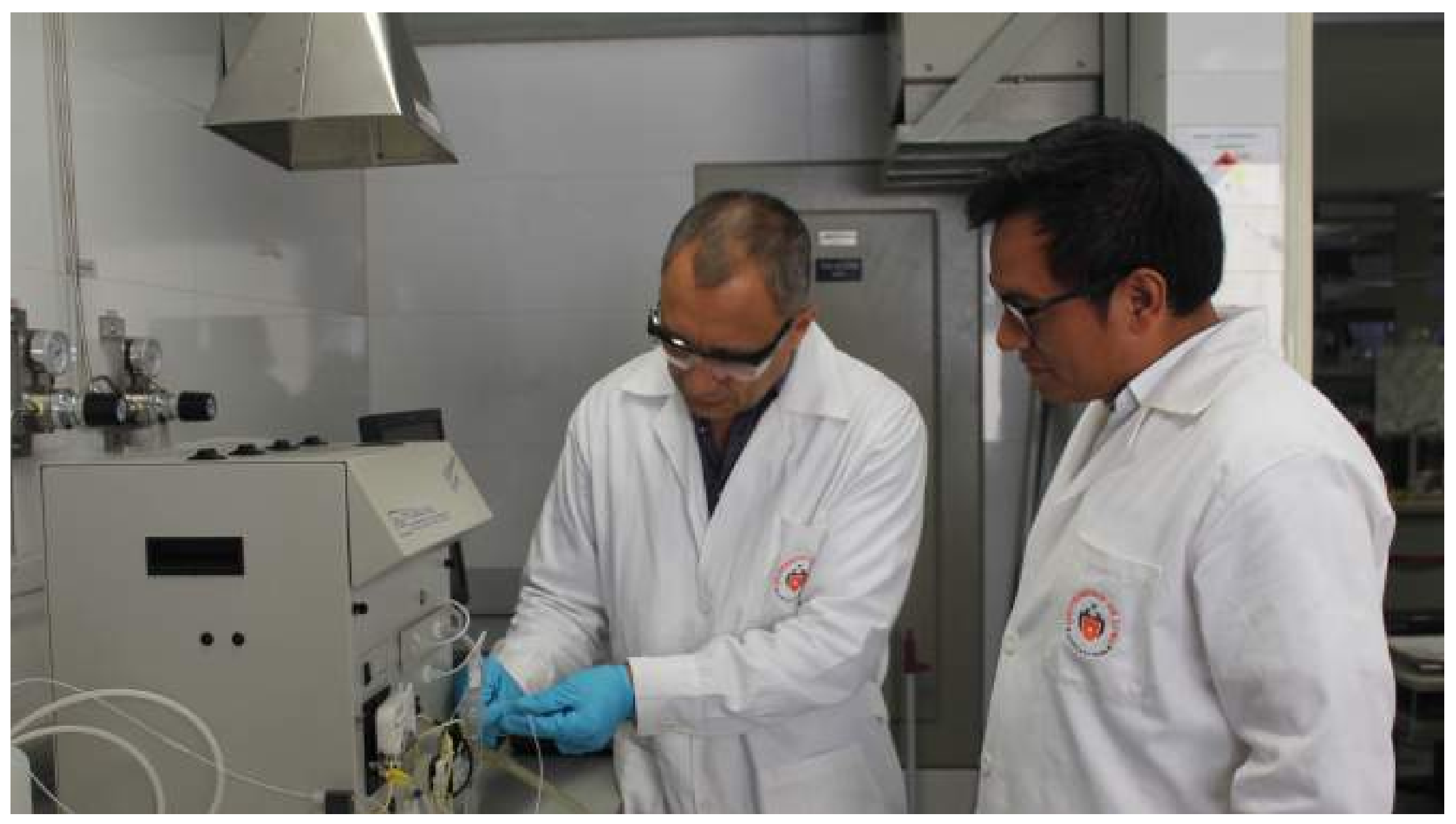

Figura 5. Análisis de los componentes del agua

Fuente: archivo fotográfico del Centro de Estudios para el Desarrollo Sostenible de la Universidad de Lima 


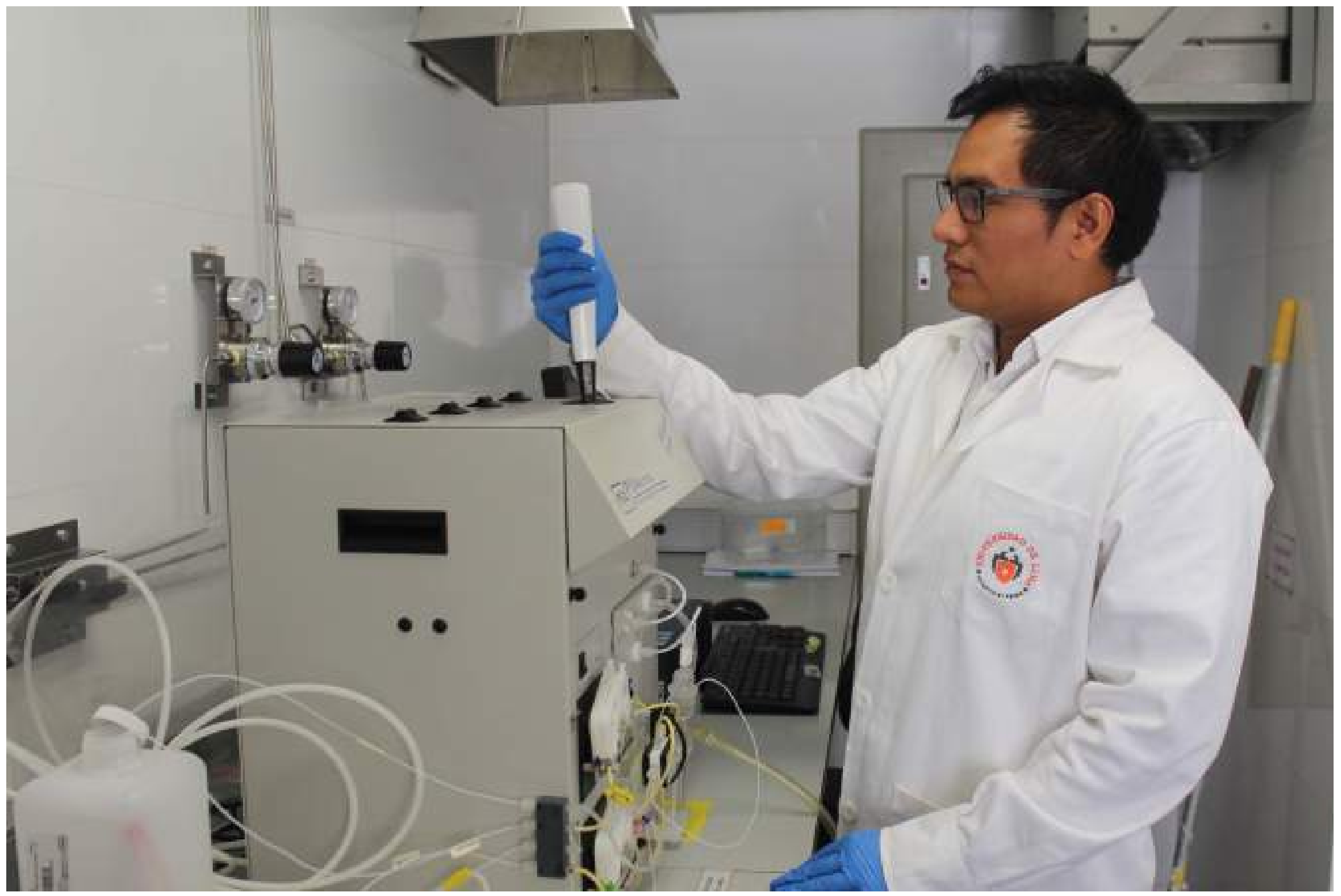

Figura 6. Análisis del agua

Fuente: archivo fotográfico del Centro de Estudios para el Desarrollo Sostenible de la Universidad de Lima

\section{Referencias}

Burst. (s. f.). Person washing his hand. Recuperado de https:// www.pexels.com/photo/person-washing-his-hand-545014/

Eckenfelder, W. W. (2000). Industrial water pollution control (3. ${ }^{\text {e ed. }) . ~ P e k i ́ n: ~ M c G r a w-H i l l . ~}$

Fancycrave. (s. f.). Motorcycle in the middle of street. Recuperado dehttps://www.pexels.com/photo/motorcycle-in-the-middle-ofstreet-917372/

Holt, P. K., Barton, G. W., y Mitchell, C. A. (2005). The future for electrocoagulation as a localised water treatment technology. Chemosphere, 59(3), 355-367. http://doi.org/10.1016/j. chemosphere.2004.10.023

Lee, S. Y., y Rhee, S. K. (2005). From end-of-pipe technology towards pollution preventive approach: the evolution of corporate environmentalism in Korea. Journal of Cleaner Production, 13(4), 387-395. http://doi.org/10.1016/j.jclepro.2003.10.010

McLaughlin, L. A., McLaughlin, S. H., y Groff, K. A. (1992).
Develop an effective wastewater treatment strategy. Chemical Engineering Progress, 88(9), 34-42.

Pixabay. (s. f.). [Fotografía]. Recuperado de https://www. pexels.com/photo/beautiful-daylight-fall-korea-290604/

Rice, E. W., Baird, R. B., y Eaton, A. D. (Eds.). (2017). Standard methods for the examination of water and wastewater (23. ${ }^{\mathrm{a}}$ ed.).

Washington DC: American Public Health Association Association, American Water Works Federation, Water Environment.

Water Environment Federation. (2008). Wastewater sampling andanalysis. EnIndustrialwastewatermanagement, treatmentand disposal (3. ed.) (pp. 59-75). Alexandria, Virginia: Autor. 